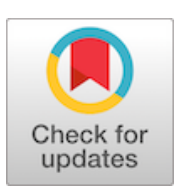

\title{
Oclusión intestinal secundaria a melanoma metastásico
}

\author{
Small bowel obstruction secondary to metastatic melanoma \\ Marta Allué-Cabañuz', Jorge Chóliz-Ezquerro²
}

$1 \mathrm{MD}, \mathrm{PhD}$, Servicio Cirugía General y Aparato Digestivo, Hospital Universitario San Jorge, Huesca

2 MD, Servicio Cirugía General y Aparato Digestivo, Hospital Universitario Miguel Servet Zaragoza

\section{Introducción}

El intestino es raramente asiento de metástasis, siendo el melanoma maligno el tumor más frecuente que las produce. Sin embargo, solo en un $5 \%$ de los casos llegan a detectarse.

\section{Caso clínico}

Paciente masculino de 73 años, con antecedente de amputación del primer dedo de mano por me- lanoma amelanótico Clark IV / Breslow 9 mm y linfadenectomía cervical, en seguimiento por Oncología, sin detectar recidiva. Cuatro años después, acude a urgencias presentando dolor abdominal y vómitos de un mes de evolución. En la tomografía computarizada (TC) abdominal se destaca un conglomerado de asas intestinales sin establecer causa (Figura 1).
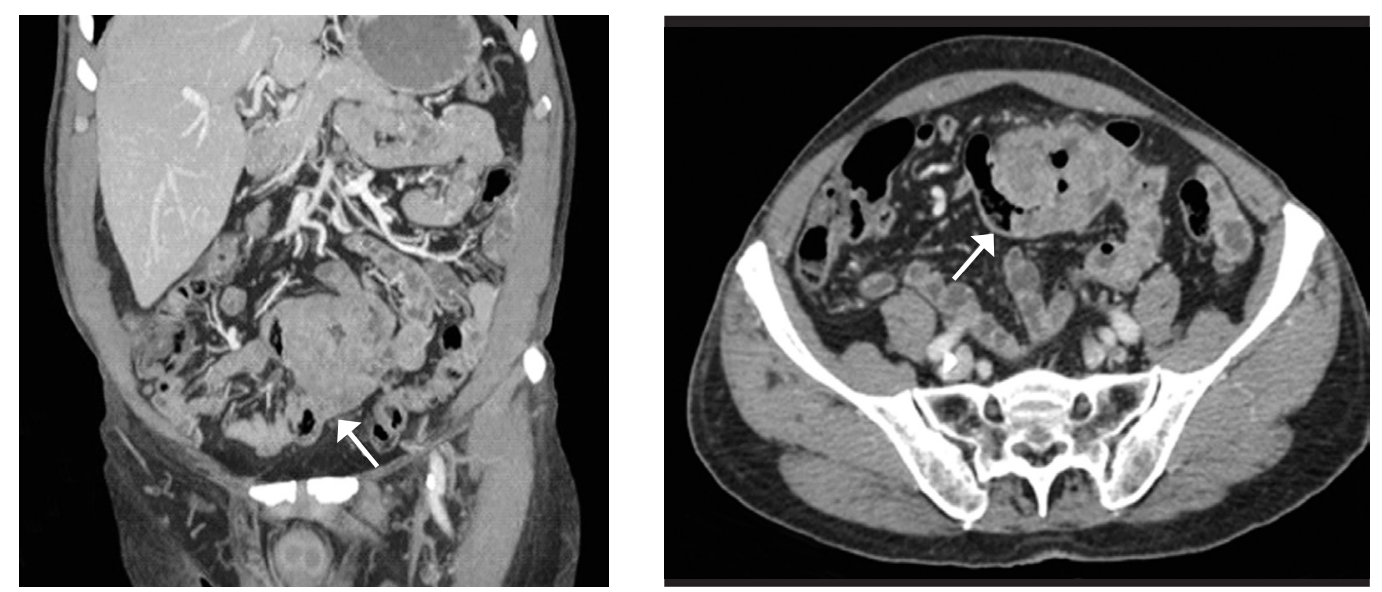

Figura 1. Tomografía computarizada abdominal donde se observa conglomerado de asas intestinales sin establecer causa (flecha).

Palabras clave: Oclusión intestinal; Abdomen agudo; metástasis intestinal; melanoma.

Keywords: Small bowel obstruction; Acute abdomen; intestinal metastases; melanoma.

Fecha de recibido: 03/01/2021 - Fecha de aceptación: 28/02/202 - Fecha de publicación en línea: 30/03/2021

Autor de correspondencia: Marta Allué Cabañuz, Avenida Martinez de Velasco 36, 22004, Huesca, España

Teléfono: 0034974247000. Email: martitaallue@hotmail.com

Citar como: Allué-Cabañuz M, Chóliz-Ezquerro J. Oclusión intestinal secundaria a melanoma metastásico. Rev Colomb Cir. 2021;36: 531-3. https://doi.org/10.30944/20117582.866.

Este es un artículo de acceso abierto bajo una Licencia Creative Commons - BY-NC-ND https://creativecommons.org/licenses/by-ncnd/4.0/deed.es 
El paciente presenta rectorragias autolimitadas, por lo que se realiza colonoscopia encontrando ulceraciones colónicas sin sangrado activo y PET-scan donde se objetiva captación compatible con tumoración tipo GIST (Figura 2).

Una semana tras el ingreso empeora clínicamente, con acidosis metabólica y criterios de sepsis. Se realiza nuevo TC (Figura 3) hallando tumoración abscedada que condiciona cuadro oclusivo y liquido libre que sugiere sufrimiento de asa intestinal. Se interviene de urgencia, encontrando tumoración en íleon terminal que compromete dos asas intestinales, una de ellas torsionada sobre sí misma causando la oclusión. Se practica resección intestinal con la tumoración en bloque, con evolución postoperatoria favorable. La anatomía patológica confirmó metástasis de melanoma, infiltrante y ulcerado, alcanzando todas las capas de la pared, con márgenes libres.

\section{Conclusiones}

El estudio de pacientes con historia de melanoma que presenten síntomas gastrointestinales debe incluir evaluación radiológica y endoscópica, considerando las metástasis como el diagnóstico diferencial más importante a descartar.

\section{Cumplimiento de normas éticas}

Consentimiento del paciente: El paciente declaró la aceptación de la utilización de imágenes relativas a su caso clínico en el ámbito de investigación, preservando

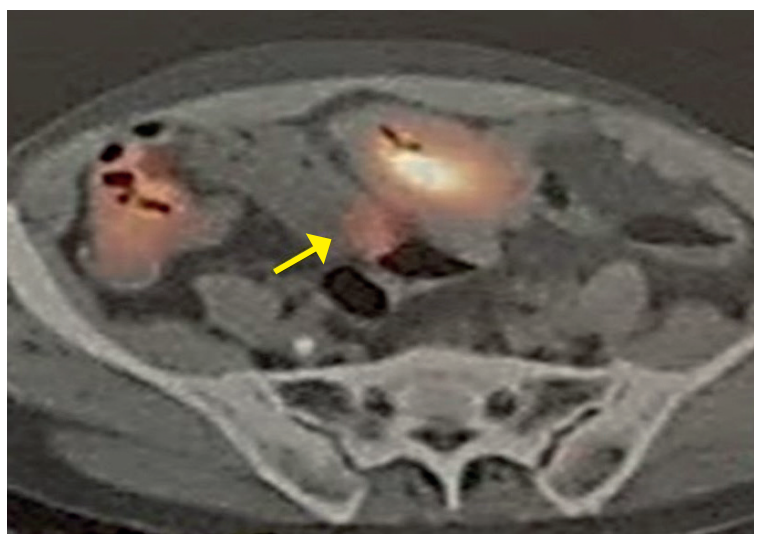

Figura 2. PET-TAC permite ver captación compatible con tumoración GIST (flecha) su anonimato, y firmó el consentimiento informado estándar al respecto.

Declaración de los conflictos de interés: Los autores declaran no haber recibido financiación ni tener conflictos de interés.

Financiación: Autofinanciado por los autores.

Contribución de los autores:

- Concepción y diseño del estudio: Marta Allué.

- Adquisición de datos: Marta Allué.

- Análisis e interpretación de datos: Marta Allué y Jorge Chóliz.

- Redacción del manuscrito: Marta Allué y Jorge Chóliz.

- Revisión crítica: Marta Allué.
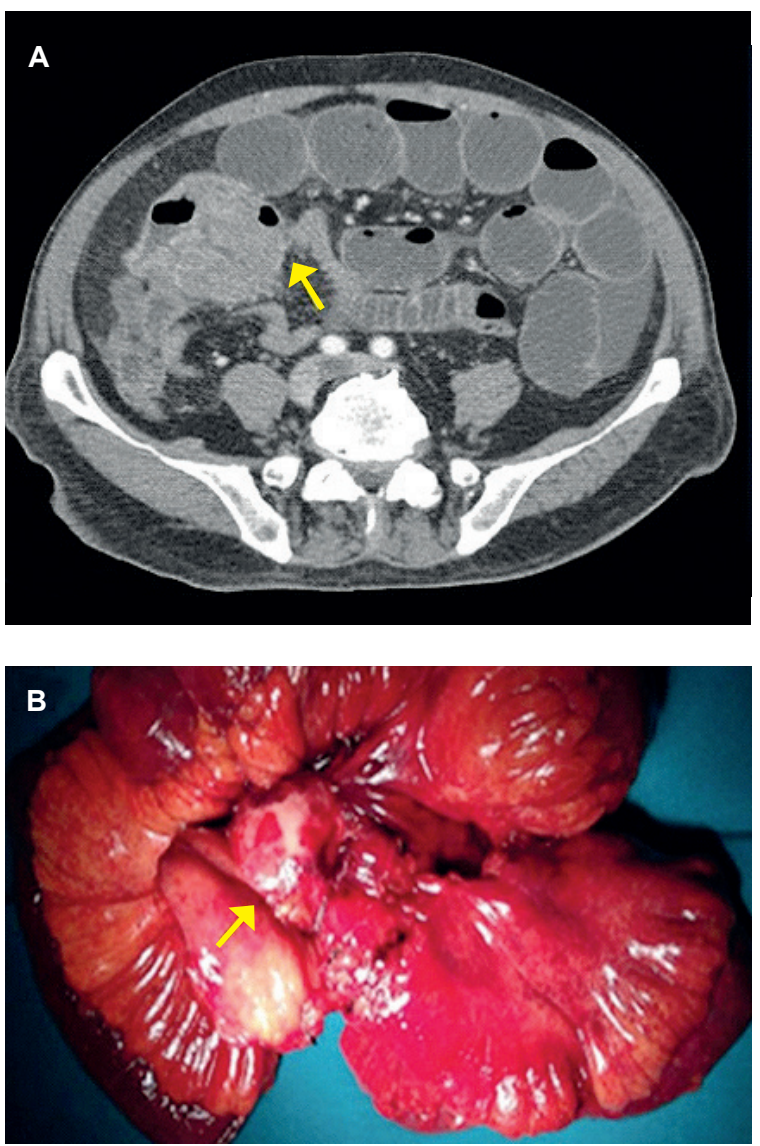

Figura 3. A. Tomografía computarizada abdominal muestra tumoración abscedada que ocasiona cuadro oclusivo (flecha). B. Pieza quirúrgica con tumoración en íleon terminal que engloba dos asas intestinales, una de ellas torsionada sobre sí misma condicionando la oclusión (flecha). 


\section{Referencias}

1. Perez MC, Sun J, Farley C, Han D, Sun AH, Narayan $\mathrm{D}$, et al. Management of intussusception in patients with melanoma. J Surg Oncol. 2019;119:897-902. https://doi.org/10.1002/jso.25393

2. Đokić M, Badovinac D, Petrič M, Trotovšek B. An unusual presentation of metastatic malignant melano- ma causing jejuno-jejunal intussusception: a case report. J Med Case Rep. 2018;12:337.

https://doi.org/10.1186/s13256-018-1887-5

3. Li WX, Wei Y, Jiang Y, Liu YL, Ren L, Zhong YS, et al. Primary colonic melanoma presenting as ileocecal intussusception: case report and literature review. World J Gastroenterol. 2014;20:9626-30.

https://doi.org/10.3748/wjg.v20.i28.9626 